\title{
Parvovirus B19 Intrauterine Infection and Eventration of the Diaphragm
}

\section{Georgios Mitsiakos ${ }^{1}$, Christoforos Gavras', Georgios N. Katsaras ${ }^{1}$, Ilias Chatziioannidis', Vasilios Mouravas², Christina Mitsiakou", Vasilios Lampropoulos ${ }^{2}$, Nikolaos Nikolaidis ${ }^{1}$}

${ }^{1} 2^{\text {nd }}$ Neonatal Department and Neonatal Intensive Care Unit, Aristotle University of Thessaloniki, "Papageorgiou” General Hospital of Thessaloniki, Thessaloniki, Greece; ${ }^{2} 2^{\text {nd }}$ Department of Pediatric Surgery, Aristotle University of Thessaloniki, "Papageorgiou" Hospital, Thessaloniki, Greece

Received November 22, 2021; Accepted January 31, 2022.

Key words: Diaphragmatic eventration - Neonate - Fetus - Parvovirus B19

Abstract: Parvovirus B19 infection in pregnancy may have a poor outcome for the fetus. Ocular anomalies, brain damage with hydrocephalus and central nervous system (CNS) scarring, cleft lip and hypospadias, as well myocarditis and congenital heart disease have been reported. We present a case of a preterm female neonate born with ascites, hydrothorax and congenital diaphragmatic eventration (CDE), with a prenatal diagnosis of congenital diaphragmatic hernia $(\mathrm{CDH})$. The neonate was born prematurely at 32 weeks gestation with caesarean section due to a previous caesarean delivery. She was immediately intubated in the delivery room, transferred in the Neonatal Intensive Care Unit (NICU) and supported with high frequency oscillatory ventilation (HFOV). The diagnosis of $\mathrm{CDH}$ was sonographically estimated from the $20^{\text {th }}$ week of gestation and surgical correction was decided. During surgery $\mathrm{CDE}$ was diagnosed instead of $\mathrm{CDH}$ and despite postoperatively care the neonate developed disseminated intravascular coagulation and finally died in the $40^{\text {th }}$ hour of life. Along with the identification of parvovirus B19 in the pleural fluid by PCR, the biopsy of the diaphragm revealed connective tissue, full of vasculature and absence muscle tissue. Although only cytomegalovirus, rubella, and toxoplasmosis were considered to be associated with CDE, parvovirus B19 might also be related to this congenital diaphragmatic malformation. In CDE, the function of the lungs can be compromised as a consequence of the compression applied by the abdominal organs. The neonatologists should include this condition in their differential diagnosis for a more direct and effective management.

Mailing Address: Assoc. Prof. Georgios Mitsiakos, MD., PhD., Ring Road, Nea Efkarpia 56403, Thessaloniki, Greece; Phone: 0030231332 336; Mobile Phone: 003069747289 79; e-mail: mitsiakos@auth.gr 


\section{Introduction}

Human parvovirus B19 was first identified by Cossart et al. in 1975 in the serum of normal blood bank donors after being screened for the hepatitis $B$ virus. In 1983, Anderson et al. reported parvovirus B19 as the probable cause of erythema infectiosum, also known as fifth disease. The first association of parvovirus B19 infection in pregnancy with poor outcome was in 1984, when hydropic fetuses were shown to have anti-B19 immunoglobulin M (IgM) (Brown et al., 1984). Multiple studies regarding congenital infections have confirmed this association (Matsunaga et al., 1987; Maeda et al., 1988; Sahakian et al., 1991; Faure et al., 1996; Mielke and Enders, 1996). Congenital diaphragmatic eventration (CDE) is generally defined as an abnormal displacement of a portion or whole of an attenuated but otherwise intact diaphragm into the thoracic cavity. Clinically it mimics the features of congenital diaphragmatic hernia $(\mathrm{CDH})$ with displacement of abdominal organs into the thorax (Clifton and Wulkan, 2017).

We hereby present a case of a preterm female neonate born with ascites, hydrothorax and congenital diaphragmatic eventration (CDE).

\section{Case report}

A female neonate was prematurely born after 32 weeks of gestation with caesarean section due to a previous caesarean delivery. She was immediately intubated in the delivery room and afterwards she then transferred in the Neonatal Intensive Care Unit (NICU), where support with high frequency oscillatory ventilation (HFOV) was provided. Surfactant was administered and iNO treatment was initiated. The hematologic and biochemical investigations upon admission were normal, except for a moderate anaemia (Table 1 ).

A chest $\mathrm{X}$-ray verified the existence of right congenital diaphragmatic hernia in accordance with the pre-existing ultrasound diagnosis of $\mathrm{CDH}$ at the $20^{\text {th }}$ week of gestation. The chest $\mathrm{X}$-ray revealed a bowel gas pattern and herniation of the liver

\section{Table 1 - Hematologic and biochemical investigations}

\begin{tabular}{lc|lc}
\hline WBC & $8,130 / \mu \mathrm{l}$ & Urea & $17 \mathrm{mg} / \mathrm{dl}$ \\
Gr & $32.7 \%$ & Creatinine & $0.70 \mathrm{mg} / \mathrm{dl}$ \\
Ly & $50.9 \%$ & $K$ & $3.85 \mathrm{mmol} / \mathrm{l}$ \\
Mo & $8.4 \%$ & Na & $133.3 \mathrm{mmol} / \mathrm{l}$ \\
Eo & $1.1 \%$ & Cholesterol & $100 \mathrm{mg} / \mathrm{dl}$ \\
RBC & $3.14 \times 106 / \mu \mathrm{l}$ & Triglyceride & $19 \mathrm{mg} / \mathrm{dl}$ \\
Hb & $12.1 \mathrm{~g} / \mathrm{dl}$ & Total bilirubin & $1.78 \mathrm{mg} / \mathrm{dl}$ \\
Hct & $37.3 \%$ & SGOT & $69 \mathrm{IU} / \mathrm{I}$ \\
PLT & $295,000 / \mu \mathrm{l}$ & SGPT & $6 \mathrm{IU} / \mathrm{l}$ \\
\hline
\end{tabular}

Eo - eosinophils; Gr - granulocytes; Hb - haemoglobin; Hct - haematocrit; Ly - lymphocytes; Mo - monocytes; PLT - platelet count; RBC - red blood cell count; WBC - white blood cell count; SGOT - serum glutamic-oxaloacetic transaminase; SGPT - serum glutamic-pyruvic transaminase 
Table 2 - Biochemical examination of the pleural fluid

\begin{tabular}{ll}
\hline Volume & $55 \mathrm{ml}$ \\
Hue & yellow, slightly opaque \\
Cells & $5,070 / \mu l$ \\
Lymphocytes & majority protein \\
Albumin & $1.59 \mathrm{~g} / \mathrm{dl}$ \\
$\mathrm{LDH}$ & $82 \mathrm{U} / \mathrm{l}$ \\
Glucose & $63 \mathrm{mg} / \mathrm{dl}$ \\
Amylase & $6 \mathrm{U} / \mathrm{l}$ \\
\hline
\end{tabular}

$\mathrm{LDH}$ - lactate dehydrogenase

in the right hemithorax (Figure 1). Upper gastrointestinal (GI) series showed the small intestine in the thoracic cavity (Figure 2A and B). Echocardiography revealed a patent ductus arteriosus and an atrial septal defect with right-left leakage. $55 \mathrm{ml}$ of pleural fluid were drained from the right side. Pleural fluid biochemical analysis was compatible with a transudate (Table 2), while PCR testing identified parvovirus B19 genome. Both pleural fluid and blood cultures were negative. Diaphragm biopsy was consistent with a connective tissue, full of vasculature and lacking muscle tissue (Figure $3 \mathrm{~A}$ and $\mathrm{B}$ ).

It was then decided to proceed to surgery via an abdominal incision. On the table, a CDE diagnosis was established instead of the assumpted diagnosis of $\mathrm{CDH}$. Therefore, the initial plan changed, and the diaphragm was plicated with four rows of 3-0 Prolene sutures.

Dramatic deterioration of the clinical condition due to a disseminated intravascular coagulation (DIC) developed post operatively and the neonate died within few

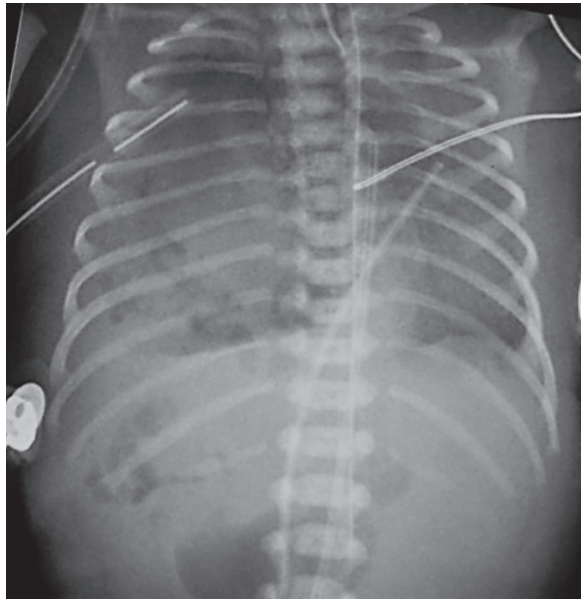

Figure 1 - First chest X-ray: a bowel gas pattern in the right hemithorax and herniation of the liver. 

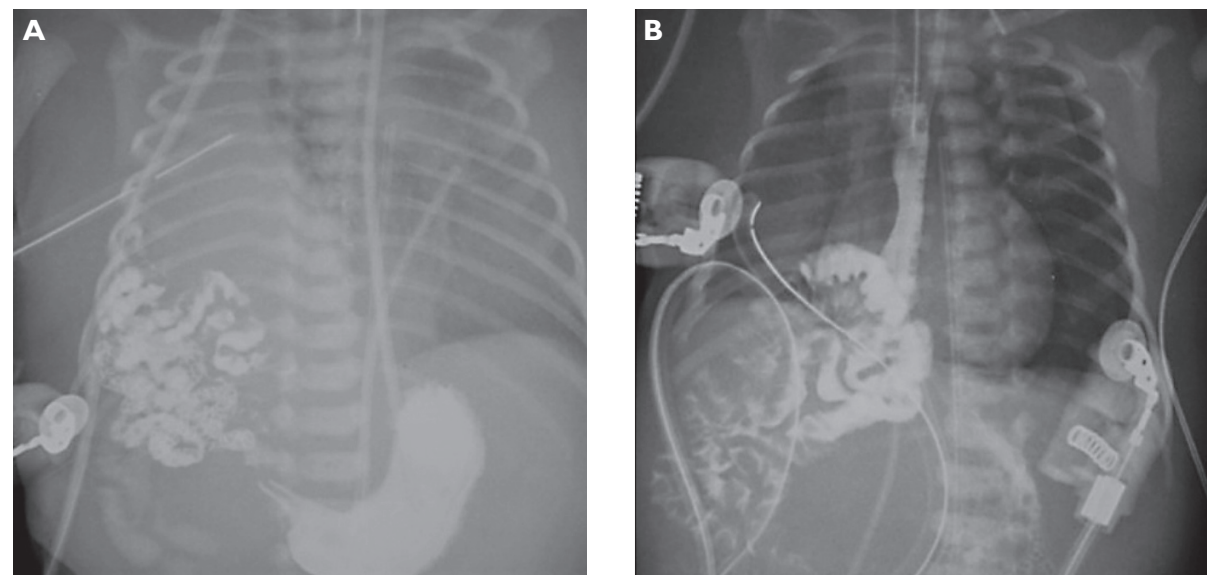

Figure 2 - Gastrointestinal passage examination: small intestine is delineated in the thoracic cavity.
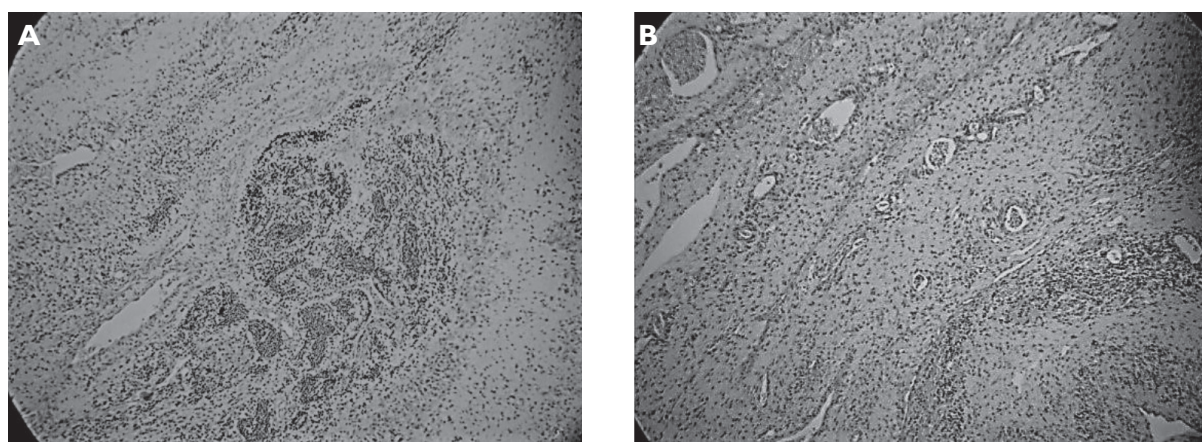

Figure 3 - Histological septal incisions characterized by lack of muscle cells, loose connective tissue, rich vascularity and lymphocytic infiltrations.

hours - just after 40 hours of life. Because of that outcome we couldn't further investigate for potential genetic syndromes with severe malformations.

\section{Discussion}

The diaphragm develops from four embryologic structures: the septum transversum, pleuroperitoneal membranes, the dorsal mesentery of the oesophagus and body wall muscles. The diaphragm develops between the $8^{\text {th }}$ and $10^{\text {th }}$ week and divides the coelomic cavity into a pleural and a peritoneal space. The aetiology of CDE is postulated to be the abnormal migration of myoblasts into septum transversum and pleuroperitoneal membrane when the midgut returns prematurely from its extracoelomic herniation to the peritoneal cavity before week ten of gestation (Tarver et al., 1984). 
The eventration process can have varying degrees of diaphragmatic involvement. Histologically a thin muscle plate or even complete absence of muscles might be found. In the latter cases the thin membrane is characterized by the presence of three layers: one composed of mesothelial cells representing the pleura, a layer of diffuse fibrous tissues representing the malformed diaphragm and a third layer representing the peritoneum (Tarver et al., 1984; Schumpelick et al., 2000; Soni et al., 2005).

Diaphragmatic eventration accounts for about $5 \%$ of all diaphragmatic anomalies (Saleh et al., 2012). Complete eventrations tend to be more frequent in males and left sided, whereas partial forms are more often described on the right side (Christensen, 1959). Diaphragmatic eventration can be classified as congenital or acquired. The acquired type occurs as a consequence of phrenic nerve injury, while the congenital is due to incomplete or absent muscularization of the pleuroperitoneal membrane during intrauterine development (Clifton and Wulkan, 2017; Pradhan et al., 2020).

Parvovirus B19 is a small, single-stranded, non-enveloped DNA virus of the Parvoviridae family. Parvovirus B19 has a predilection for rapid division of cells such as red blood cells, affecting the final stage of their maturation, causing both haemolysis and red blood cell aplasia. The $\mathrm{P}$ antigen on red blood cells is a cellular receptor of the parvovirus B19. Only 1 in 200,000 humans is $P$ negative and those persons are resistant to parvovirus B19 infection (Heegaard and Brown, 2002).

The teratogenicity of parvovirus has not yet been fully determined, although fetal malformations have been occasionally reported. Ocular anomalies, brain damage with hydrocephalus and central nervous system (CNS) scarring, cleft lip and hypospadias have been reported in association with acute intrauterine parvovirus B19 infection. Myocarditis and congenital heart disease (e.g. ventricular septal defect) have been described as well (Matsunaga et al., 1987; Sahakian et al., 1991; Tiessen et al., 1994; Mielke and Enders, 1996; Konstantinidou et al., 2007; Masini et al., 2017). Like canine parvovirus in puppies, B19 virus seems to have an affinity for fetal muscle cells, as can be concluded from findings in the heart, skeletal muscle, and umbilical artery. The reason why the heart tissue and the arteries are particularly damaged is not clearly understood. A plausible explanation could be that it might be related to a focal endothelial damage, in the way parvovirus infection manifests in swine and rat. Moreover, skeletal muscle tissue seems to be more generally affected (Hartwig et al., 1989). To our knowledge the association of CDE and intrauterine parvovirus B19 infection has not been previously described.

Most women are immune to parvovirus B19 before pregnancy (Barros De Freitas et al., 1999; Di Domenico et al., 2002; Ornoy and Ergaz, 2017). During pregnancy the risk of acquired parvovirus B19 infection is quite low, ranging from 0 to 16.5\% (Barros De Freitas et al., 1999; Makhseed et al., 1999; Tolfvenstam et al., 2001; Di Domenico et al., 2002; Baschat et al., 2003). The prevalence of maternal infection is higher during epidemics, with seroconversion rate ranging 
from 3 to 34\% (Woernle et al., 1987; Kerr et al., 1994). The risk of adverse fetal outcome is increased if maternal infection occurs during the first two trimesters of pregnancy and far more rarely during the third trimester (Ornoy and Ergaz, 2017). The transmission rate of maternal parvovirus B19 infection to the fetus is 17 to 33\% (Gratacós et al., 1995). Although parvovirus has no adverse effects on the healthy pregnant mother, its transplacental transmission to the fetus is an important cause of intrauterine death, abortion and stillbirth. These outcomes can occur after symptomatic or asymptomatic maternal infection. The virus infects liver which is the main site of erythrocyte production in the embryo (Ornoy and Ergaz, 2017). The fetus is more vulnerable during the second trimester as the liver is the main source of hematopoietic activity and red blood cells half-life of is short (50-75 days) in comparison to later hematopoietic stages. Severe anaemia can lead to congestive heart failure and development of hydrops fetalis. The risk of fetal complications - as mentioned above - depends largely upon gestational age at the time of maternal infection with parvovirus B19. Maternal infection during the first 9-16 weeks of pregnancy carries the highest risk for fetal loss; it is largely reduced during the second half of pregnancy and even more in the last 2 months (Yaegashi et al., 1994; Nyman et al., 2002). In our case, the neonate had severe hydrops fetalis with mild anaemia, probably because the cause of the ascites wasn't the anaemia but the $\mathrm{CDE}$. Although the nature of this pathology is not well known, the pathogenesis of hydrops in fetuses with malformations like $\mathrm{CDH}$ is considered secondary to the obstruction of the superior and inferior venae cavae in addition to the hepatic venous returns (Sydorak et al., 2002; Shojai et al., 2004; Rossi et al., 2014).

\section{Conclusion}

The complex development of the diaphragm plays a direct role on the occurrence of congenital diaphragmatic pathologies. In CDE, lung function can be heavily compromised by the abdominal organ compression applied. Neonatologists should be familiar with this clinical condition and include it in their differential diagnosis for a more direct and effective management.

\section{References}

Anderson, M. J., Jones, S. E., Fisher-Hoch, S. P., Lewis, E., Hall, S. M., Bartlett, C. L., Cohen, B. J., Mortimer, P. P., Pereira, M. S. (1983) Human parvovirus, the cause of erythema infectiosum (fifth disease)? Lancet 1(8338), 1378.

Barros De Freitas, R., Buarque De Gusmão, S. R., Durigon, E. L., Linhares, A. C. (1999) Survey of parvovirus B19 infection in a cohort of pregnant women in Belém, Brazil. Braz. J. Infect. Dis. 3(1), 6-14.

Baschat, A. A., Towbin, J., Bowles, N. E., Harman, C. R., Weiner, C. P. (2003) Prevalence of viral DNA in amniotic fluid of low-risk pregnancies in the second trimester. J. Matern. Fetal Neonatal Med. 13(6), 381-384.

Brown, T., Anand, A., Ritchie, L. D., Clewley, J. P., Reid, T. M. (1984) Intrauterine parvovirus infection associated with hydrops fetalis. Lancet 2(8410), 1033-1034.

Christensen, P. (1959) Eventration of the diaphragm. Thorax 14(4), 311-319. 
Clifton, M. S., Wulkan, M. L. (2017) Congenital diaphragmatic hernia and diaphragmatic eventration. Clin. Perinatol. 44(4), 773-779.

Cossart, Y. E., Field, A. M., Cant, B., Widdows, D. (1975) Parvovirus-like particles in human sera. Lancet 1(7898), 72-73.

Di Domenico, C., Moschese, V., Chini, L., Zirletta, E., Cancrini, C., Di Paolo, A., Rossi, P., Scalamandrè, A. (2002) Perinatal infections of B19 parvoviruses. Ig. Sanita Pubbl. LVIII(3), 155-162. (in Italian)

Faure, J. M., Giacalone, P. L., Deschamps, F., Boulot, P. (1996) Nonimmune hydrops fetalis caused by intrauterine human parvovirus B19 infection: A case of spontaneous reversal in utero. Fetal Diagn. Ther. 12(2), 66-67.

Gratacós, E., Torres, P. J., Vidal, J., Antolín, E., Costa, J., Jiménez de Anta, M. T., Cararach, V., Alonso, P. L., Fortuny, A. (1995) The incidence of human parvovirus B19 infection during pregnancy and its impact on perinatal outcome. J. Infect. Dis. 171(5), 1360-1363.

Hartwig, N. G., Vermeij-Keers, C., Van Elsacker-Niele, A. M., Fleuren, G. J. (1989) Embryonic malformations in a case of intrauterine parvovirus B19 infection. Teratology 39(3), 295-302.

Heegaard, E. D., Brown, K. E. (2002) Human parvovirus B19. Clin. Microbiol. Rev. 15(3), 485-505.

Kerr, J. R., O'Neill, H. J., Coyle, P. V., Thompson, W. (1994) An outbreak of parvovirus B19 infection; A study of clinical manifestations and the incidence of fetal loss. Ir. J. Med. Sci. 163(2), 65-67.

Konstantinidou, A. E., Syridou, G., Spanakis, N., Tsakris, A., Agrogiannis, G., Patsouris, E. (2007) Association of hypospadias and cardiac defect in a parvovirus B19-infected stillborn: A causality relation? J. Infect. 54(1), e41-e45.

Maeda, H., Shimokawa, H., Satoh, S., Nakano, H., Nunoue, T. (1988) Nonimmunologic hydrops fetalis resulting from intrauterine human parvovirus B-19 infection: Report of two cases. Obstet. Gynecol. 72(3 Pt 2), 482-485.

Makhseed, M., Pacsa, A., Ahmed, M. A., Essa, S. S. (1999) Pattern of parvovirus B 19 infection during different trimesters of pregnancy in Kuwait. Infect. Dis. Obstet. Gynecol. 7(6), 287-292.

Masini, L., Apicella, M., De Luca, C., Valentini, P., Manfredi, R., Lanzone, A., De Santis, M. (2017) Fetal central nervous system and infectious diseases. Donald School J. Ultrasound Obstet. Gynecol. 11(4), 314-327.

Matsunaga, Y., Matsukura, T., Yamazaki, S., Sugase, M., Izumi, R. (1987) Hydrops fetalis caused by intrauterine human parvovirus infection. Jpn. J. Med. Sci. Biol. 40(4), 165-169.

Mielke, G., Enders, G. (1996) Late onset of hydrops fetalis following intrauterine parvovirus B19 infection. Fetal Diagn. Ther. 12(1), 40-42.

Nyman, M., Tolfvenstam, T., Petersson, K., Krassny, C., Skjöldebrand-Sparre, L., Broliden, K. (2002) Detection of human parvovirus B19 infection in first-trimester fetal loss. Obstet. Gynecol. 99(5 Pt 1), 795-798.

Ornoy, A., Ergaz, Z. (2017) Parvovirus B19 infection during pregnancy and risks to the fetus. Birth Defects Res. 109(5), 311-323.

Pradhan, P., Karmacharya, R. M., Vaidya, S., Singh, A. K., Thapa, P., Dhakal, P., Dahal, S., Bade, S., Bhandari, N. (2020) Case report of eventration of diaphragm due to an unknown febrile illness causing phrenic nerve palsy and other multiple nerve palsies. Ann. Med. Surg. (Lond.) 54, 74-78.

Rossi, A., Delabaere, A., Delmas-Laurichesse, H., Beaufrère, A. M., Lémery, D., Gallot, D. (2014) The challenge of prenatal identification of congenital diaphragmatic hernia in the context of hydrops. Eur. J. Obstet. Gynecol. Reprod. Biol. 182, 238-239.

Sahakian, V., Weiner, C. P., Naides, S. J., Williamson, R. A., Scharosch, L. L. (1991) Intrauterine transfusion treatment of nonimmune hydrops fetalis secondary to human parvovirus B19 infection. Am. J. Obstet. Gynecol. 164(4), 1090-1091. 
Saleh, M., Suwaid, M., Idris, S., Tabari, A., Isyaku, K. (2012) Diaphragmatic eventration mimicking congenital diaphragmatic hernia: The value of chest radiograph and barium meal in diagnosis. Niger. J. Basic Clin. Sci. 9(1), 36-39.

Schumpelick, V., Steinau, G., Schlüper, I., Prescher, A. (2000) Surgical embryology and anatomy of the diaphragm with surgical applications. Surg. Clin. North Am. 80(1), 213-239, xi.

Shojai, R., Gire, C., Chaumoître, K., Merrot, T., Panuel, M., Boubli, L., D’Ercole, C. (2004) Right diaphragmatic hernia and hydrops: Is it always fatal? Ultrasound Obstet. Gynecol. 24(7), 803-804.

Soni, A., Singh, P., Singh, R., Sood, V. (2005) Eventration of diaphragm - Embryologic basis. J. Anat. Soc. India 54(2), 1-9.

Sydorak, R. M., Goldstein, R., Hirose, S., Tsao, K., Farmer, D. L., Lee, H., Harrison, M. R., Albanese, C. T. (2002) Congenital diaphragmatic hernia and hydrops: A lethal association? J. Pediatr. Surg. 37(12), 16781680.

Tarver, R. D., Godwin, J. D., Putman, C. E. (1984) Symposium on Nonpulmonary Aspects in Chest Radiology. The diaphragm. Radiol. Clin. North Am. 22(3), 615-631.

Tiessen, R. G., van Elsacker-Niele, A. M., Vermeij-Keers, C., Oepkes, D., van Roosmalen, J., Gorsira, M. C. (1994) A fetus with a parvovirus B19 infection and congenital anomalies. Prenat. Diagn. 14(3), 173-176.

Tolfvenstam, T., Papadogiannakis, N., Norbeck, O., Petersson, K., Broliden, K. (2001) Frequency of human parvovirus B19 infection in intrauterine fetal death. Lancet 357(9267), 1494-1497.

Woernle, C. H., Anderson, L. J., Tattersall, P., Davison, J. M. (1987) Human parvovirus B19 infection during pregnancy. J. Infect. Dis. 156(1), 17-20.

Yaegashi, N., Okamura, K., Yajima, A., Murai, C., Sugamura, K. (1994) The frequency of human parvovirus B19 infection in nonimmune hydrops fetalis. J. Perinat. Med. 22(2), 159-163. 